\title{
Recent Trends of Educational Technology For Egypt 2018
}

\section{Dr. Amira Reda Mosad}

Ph.D in Educational Technology

\section{ABSTRACT}

The main purpose of this research is to survey the recent
literature in the field of educational technology in order to
collect the latest trends of educational technology to help the Egyptian students, researchers, and the academic staff specialized in educational technology. The research used descriptive research method. Research Results: Here are the 30 trends in technology and education to look out for in 2018:

Key words : Recent Trends - Educational Technology -

\section{Introduction:}

As school objectives evolve and technology advances, new teaching methods and EdTech trends emerge each year. Technology in education constantly disrupts and enhances pedagogy. It paves the way for new learning experiences and provides innovative ways to achieve core goals for the next academic year. Each year, it is exciting to take a look at the emerging trends in education and speculate on how edtech will continue to impact student learning in the future. As technology continues to develop along with awareness of the need to increase edtech accessibility and training, an entirely new landscape for teaching and learning unfolds. Below are four trends in education that are expected to change the frontier of learning by the end of 2018.

\section{Research Major Question:}

What are the latest trends in 2018 of the educational technology at the local and international levels?

\section{Research Objectives:}

To survey the recent literature in the field of educational technology in order to collect the latest trends of educational 
technology to help the Egyptian students, researchers, and the academic staff specialized in educational technology.

\section{Research Importance:}

1. To help new researcher in colleges education in Egypt to select new topics for their research plans.

2. To assist academic staff and supervisors of research in educational technology departments to update their researches and studies.

3. To reengineer and update the academic practices in field of educational technology in Egypt and the Arab world.

\section{Research Procedures:}

1. Surveying the educational technological literature since 2015 till 2018

2. Collecting the latest, recant and emerging educational technology trends.

3. Sorting and ordering the collect educational technology trends.

4. Identifying the utmost recent trends in educational technology for 2018.

5. Writing a brief note about each selected trend and documented it.

\section{Research Method:}

The research used descriptive research method.

\section{Research Limits:}

1. Recent trends in teaching and learning through technology.

2. Literature review published at 2015-2018.

\section{Research Results:}

Here are the 30 trends in technology and education to look out for in 2018:

\section{Cloud-based Technology}

In 2018, cloud computing will continue to make learning a more streamlined experience. Students will no longer worry 
about files and documents being lost or deleted, or buying multiple USB flash drives to save their assignments. Essays, content related to projects, schedules and assignments will be shared more easily and securely stored on the cloud, such as Google Docs. With more centralized storage for resources, cloudbased technology will allow educators to increase their reach and share information without increased expenditure, or additional time pressure. (Promethean World, 2018).

\section{Virtual and Augmented Reality}

New technology will provide teachers with tools for delivering enhanced learning experiences through augmented and virtual reality (VR) in 2018. After the success of Pokemon Go, we witnessed the emergence of augmented reality (AR) in education in 2017. Teachers are increasingly using AR to layer virtual content on printed materials to enhance understanding and inspiration. With the release of increasingly affordable and accessible VR accessories, we can expect more from this technology in 2018. The number of free apps and teaching platforms designed specifically for virtual education is growing. VR and AR will move from experimental to ubiquitous in learning. Work with your IT team to review the available devices, and make sure you investigate the costs of emulating a real work environment effectively (Promethean World, 2018).

\section{STEAM - arts and STEM}

There has been a strong pedagogical focus to increase the digital literacy of students, and encourage more students to adopt tech-focused subjects over the past few years. This has ensured they grow into more responsible users of the internet, as well as fostering key transferable skills for their futures. According to our research on the use of technology in education in 2017, STEM classes are perceived as the most technologicallyadvanced of the curriculum. More traditional arts and humanities subjects, however, are recognized as catching up in their use of EdTech.Trends in technology, and the increased use of edtech across the entire curriculum, indicates that creativity will return to the forefront of education. Incorporating elements of 
creativity into STEM subjects has undeniable benefits including increasing the accessibility across genders, and engaging different types of learners. The STEAM approach will take more shape in 2018(Promethean World, 2018).

\section{Technology to Prevent Bullying}

With the prolific nature of mobile devices and social platforms, it's a sad truth that online bullying is becoming increasingly common. While technology is an enabler for abusive behavior, it will go on to provide more robust solutions to the problem in 2018.Edtech will be used extensively in 2018 to monitor student technology, track the use of search terms that they use, as well as all visited websites. More apps will allow teachers and IT administrators to remotely view any of their students' devices. Other technologies will be applied directly to student devices to monitor tone of voice, location services, image scanning, keyword flagging and social media activity, to give an overall picture of a child's mood. Platforms to provide a means of reporting and communication between teachers and students will grow in popularity. These tools raise awareness of the widespread bullying issue, and enhance methods of communication (Promethean World, 2018).

\section{Mobile-Style Education}

Today, many students own a mobile device. Tapping this technology for learning in 2018 will improve engagement and motivation across all learning abilities. Mobile learning will also offer greater flexibility and accessibility for learning at home. Connecting mobile technology and devices within the classroom will allow teachers to provide a fully immersive, integrated learning experience for all learning styles and abilities. Thanks to students' intuitive use of technology, in 2018 more schools will adopt tablet-like experiences for their front-of-class displays and incorporate this with new learning techniques and the gamification of learning. Traditional interactive whiteboards are becoming harder to scale or costly to replace, whereas schools are turning to more future-proof, upgradeable technologies like Promethean ActivPanels.Innovations and trends in technology 
across businesses and enterprise are giving schools more advanced tools and better forms of edtech to improve their school's results and enhance their teachers' pedagogy. Innovative teachers, meanwhile, are getting more creative with their edtech, finding ways to use technology for differentiated learning and increased engagement. The biggest potential technology impact on students will be the opportunity to nurture skills to help them succeed, increase the quality of learning across mixed-ability classes, and protect their online safety (Promethean World, 2018).

\section{Artificial Intelligence}

In a world where we are growing more and more accustomed to (and perhaps reliant on) intelligent digital assistants like Siri for help with everyday life, it is easy to see how AI can make the jump into the classroom. Whether by offering insight into student learning, facilitating communication, or supporting teachers with grading, AI provides opportunities to transform the learning process and delegate time-consuming rote tasks, thereby leaving more time for enhanced learning (Lexia Learning, 2018).

\section{Improved Accessibility via Learning Tech}

Computer-based games, apps, and digital learning devices play an important role in the education of students with disabilities. As new tech emerges for both the home and classroom, students are better able to learn in a way that meets their needs and is more inclusive, all the while reducing the stigma of assistive technology. Audiobooks, dictation software, and reading apps already help many students with visual/auditory challenges or certain disabilities such as dyslexia. In this day and age, the increased presence of AI devices such as Amazon Echo and Google Home means students with and without disabilities are more familiar with the concept of speaking to devices, which may facilitate greater understanding and support of students who need to use assistive technology in the classroom. This also presents the opportunity for teachers to plan lessons and assignments that engage the class in device- 
based learning, thereby creating a more inclusive environment for all students (Lexia Learning, 2018).

\section{Data Privacy and Cybersecurity}

Data privacy has been on the minds of district administrators for years thanks to the increase in student device use-in fact, it was one of the big trends for 2017. With technology continuing to be integrated and broadly used in schools, cybersecurity remains a serious concern in 2018 and beyond. More than 32 million education records were compromised in the first half of 2017 alone, with the education sector making up 13 percent of total data breaches. And it is not just test scores that are compromised; student and personnel information, tax identification and financial documents are all at risk, leading to concerns over potential identity theft in addition to attacks on school infrastructure. Further compounding the problem is the fact that schools often have limited resources to deal with and prevent phishing, ransomware, and other common forms of cyberattack. As new technology and additional uses for previously integrated edtech emerge, schools in today's cybersociety should be more diligent than ever in creating a safe and productive digital environment for students. By harnessing the power of AR and AI, teachers can open the doors to learning in a whole new manner, and schools are likely to see an increase in both engagement and understanding of critical skills. When tied into successful learning practices such as blended learning and research-backed computer-based education programs, the learning of the future looks promising to say the least(Lexia Learning,2018).

\section{Game-based Learning}

When you enjoy what you do, you are more likely to be drawn to do it more and eventually you are addicted to it. "Hey, this game is so cool. I am addicted." We all can relate to it, right? Now imagine, what if one day you see a student studying and saying, he is addicted to learning? You'd probably stop imagining, but hey, it is possible with the help of gamification.Game-based learning, or as commonly known as GBL, are gaining too much 
popularity as they are powerful tools to shape the future of learning. When bound tightly to the curriculum, gamification proves to be engaging and relate highly to the students (Troo Tech, 2017)

\section{Online Social Networking : Community Based Learning}

Social media and learning - never got to see both of these words in the same sentence? Well, get habituated because social media has got many benefits for the students. It increases the proficiency in the technology and their exposure to different opinions and views which can in turn broaden their perspective. Social media has a lot of communication to do with it and students can profess communication. Moreover, social media is the most engaging way to learn. Platforms such as Quora can help the students to learn many new concepts and can share their insights. As a part of team building effort, students can collaborate with their peers and can group work on their assignments. For any doubt or queries, the students can immediately seek guidance from their teachers (Troo Tech, 2017)

\section{Google Docs and Slack}

Cloud tools like Google Docs are a perfect fit for students because of their flexibility, but also because they allow for realtime collaboration with students and teachers located anywhere. New also make it even easier for educators to build out templates in the cloud so formatting is not lost. Add-on tools supported by Google Docs make citations a breeze for students and their professors. Thanks to a new version-history module, collaboration and productivity are also eased. With notifications on progress, students will be more effective in group projects. In addition to cloud technology in higher education classwork, Nash also says communication apps like Slack can be a useful addition. In an EdTech blog, student Lauren Polito praises Slack as a great tool for group projects and fostering easy communication with educators (Cortez, 2018). 


\section{Adaptive Learning}

While many universities have used IBM Watson and Microsoft Power BI to analyze data for student success initiatives, adaptive learning programs are still an emerging technology in higher education. Experts, which blend data with elements of artificial intelligence to tailor classwork to the abilities of students, will help drive academic transformation in the future. "Adaptive learning products are already very important in assessment," says Nash. "They help map a student's knowledge and track it with outcomes and competencies. Students can build on the knowledge they have and make real strides in their ability to demonstrate their skills. "Largely, chief academic officers believe that adaptive learning technology will be integral to improving student learning outcomes, but they need more IT support to implement the tools (Cortez, 2018).

\section{Mondopad and Microsoft Surface Hubs}

To Nash, displays are a mainstay of technology tools in the classroom, whether in the form of one large screen or several small ones. Interactive displays, in particular, foster collaboration. Using Microsoft Surface Hubs, students and educators in the Cleveland Clinic Lerner College of Medicine, are able to view and annotate resources either on the board at the field site or remotely on connected devices. The Mondopad from InFocus combines an interactive whiteboard with a videoconferencingsolution, so educators can bring in experts and content from literally anywhere(Cortez,2018)..

\section{Videoconferencing Technology}

Videoconferencing technology itself has had a major impact on the college classroom. By equipping classrooms with cameras and high-definition displays, rural colleges have been able to 
bring in remote professors and offer diverse learning opportunities.Telepresence tools have also given a voice to distance students and increased their access to classroom resources. At Michigan State University, for example, telepresence robots that use videoconferencing technology have enabled remote learners to contribute to the physical space of the classroom and take part in important interactions(Cortez,2018)..

\section{One-to-One computing.}

The trend in classrooms around the world is to provide an information appliance to every learner and create learning environments that assume universal access to the technology. Whether the hardware involved is one laptop per child (OLPC), or - increasingly -- a net computer, smart phone, or the reemergence of the tablet, classrooms should prepare for the universal availability of personal learning devices (HAWKINS, 2010).

\section{Ubiquitous learning.}

With the emergence of increasingly robust connectivity infrastructure and cheaper computers, school systems around the world are developing the ability to provide learning opportunities to students "anytime, anywhere". This trend requires a rethinking of the traditional 40 minute lesson. In addition to hardware and Internet access, it requires the availability of virtual mentors or teachers, and/or opportunities for peer to peer and self-paced, deeper learning.

\section{Personalized learning.}

Education systems are increasingly investigating the use of technology to better understand a student's knowledge base from prior learning and to tailor teaching to both address learning gaps as well as learning styles. This focus transforms a classroom from one that teaches to the middle to one that adjusts content and pedagogy based on individual student needs - both strong and weak(HAWKINS,2010).. 


\section{Teacher-generated open content.}

OECD school systems are increasingly empowering teachers and networks of teachers to both identify and create the learning resources that they find most effective in the classroom. Many online texts allow teachers to edit, add to, or otherwise customize material for their own purposes, so that their students receive a tailored copy that exactly suits the style and pace of the course. These resources in many cases complement the official textbook and may, in the years to come, supplant the textbook as the primary learning source for students. Such activities often challenge traditional notions of intellectual property and copyright (HAWKINS, 2010).

\section{Smart portfolio assessment.}

The collection, management, sorting, and retrieving of data related to learning will help teachers to better understand learning gaps and customize content and pedagogical approaches. Also, assessment is increasingly moving toward frequent formative assessments which lend itself to real-time data and less on high-pressure exams as the mark of excellence. Tools are increasingly available to students to gather their work together in a kind of online portfolio; whenever they add a tweet, blog post, or photo to any online service, it will appear in their personal portfolio which can be both peer and teacher assessed(HAWKINS,2010)..

\section{Self-learning technologies}

Help students in sharing their work with others, getting feedbacks for enhancements, practice tests for pre-preparation and build project videos to look for views along with comments as well as develop their future learning plans. Self-directed learning includes free open educational resources accessible online, personal learning networks, advanced video conferencing tools, self-publishing technologies, social media platforms, YouTube, iTunes, and portfolios (beacon, 2018). 


\section{App Based Learning}

App-based learning will more and more mature in 2018. There are nearly 650 million mobile phone users in India, and $300+$ million of them have a smartphone. So, the anytime, anywhere suppleness of mobile technology is here to dwell. Learners like to use mobile and explore solutions to concentrate on their learning requirements on-the-go even devoid of an Internet connection. Mobile Apps are the real answer to fulfill these flexible learning needs. Mobile apps will further enable gamified learning, quick assessments, social learning, and micro learning. (Beacon, 2018)

\section{Knowledge Sharing}

Knowledge sharing impacts student attitude, motivation, and achievement levels. A positive feedback sphere exists between motivation and knowledge sharing. Effective tools and techniques can be included to share articles, documents by teachers, professors with group of students. The relevance of the internet and online technologies will further influence students to focus their research on social media platforms (Facebook, LinkedIn, Twitter and more), blogs and wikis. The social relationships will become a product of online interactions with students who may at times not know each other would build personal relationships subsequent to sharing knowledge about their personal experiences online (beacon, 2018)

\section{Interactive Learning Tools and Techniques}

The year 2018 is predicted to be the right time to start bringing life into the learning styles. Here are interactive learning tools and techniques that would make a difference.

\section{Trendy Interactive Learning}

Tools VoiceThread: It helps in creating discussions around many types of artifacts like videos, images, documents, and PowerPoint with the use of audio, video, and text commenting. Piazza: It involves discussions and problem-solving forums that support anonymous posts and Q\&A. Other popular tools in the market are Quizlet (flashcards), VideoAnt (video annotation), 
VideoScribe (animated presentations), LucidChart (diagramming \& concept mapping) and Articulate Storyline 2.5 (interactive presentations). (Beacon, 2018)

\section{Trendy Interactive Techniques}

Brainstorming: Interactive brainstorming is characteristically performed in groups. The technique is used to generate creative ideas. It assists students to learn to pull together. Buzz session: Promotes discussion and collaboration across the students in groups. Every student learns from each other's inputs and shared experiences. Incident process: This technique incorporates a case-study to solve real issues that involve students. The participants are given details of actual incidents and asked to create a workable solution. Other popular techniques cover Q\&A sessions, small groups having discussions on certain topics and thus involving students to provide their opinions in their personal voice. (Beacon, 2018)

\section{Innovation in Assessment Technique}

Education requires effective innovations of scale that can assist produce the needed high-quality learning results across the system. The recurrent cycle of improvement and feedback makes learning practical as well as efficient. Here are some of the innovative assessment strategies for educators to try out. (Beacon, 2018)

\section{A. Analyzing Student Work}

An immense deal of information can be accessed from students' tests, homework, and quizzes. This is especially so if the students are required to explain their thinking. When educators take the time to analyze student work, they can access more details about student's present knowledge, skill-sets, attitude, learning styles, strengths as well as weaknesses. (Beacon, 2018)

\section{B. Thinking Skill Assessment}

Thinking skill assessment is new technique initiated by Oxford University. It helps to analyze critical thinking and problem solving ability of the individual. In today's ever changing 
dynamic world it is important to have those skills set. Vast knowledge is available on the internet for free but ability of problem solving and critical thinking can set apart any individual. (Beacon, 2018)

\section{Eliminate Theory Based Exams}

In case of Theory based exams, students are supposed to write some short notes, provide explanation to particular concept. It is important to eliminate such exams and shift to online assessment where students can write their answers on computer/ mobile/ tablet screen and it can be evaluated by teacher digitally (beacon, 2018)

\section{Deep learning (DL).}

Machine learning (ML) and more specifically DL are already on the cusp of revolution. They are widely adopted in datacenters (Amazon making graphical processing units [GPUs] available for DL, Google running DL on tensor processing units [TPUs], Microsoft using field programmable gate arrays [FPGAs], etc.), and DL is being explored at the edge of the network to reduce the amount of data propagated back to datacenters. Applications such as image, video, and audio recognition are already being deployed for a variety of verticals. DL heavily depends on accelerators (see \#9 below) and is used for a variety of assistive functions (\#s 6, 7, and 10). (IEEE, 2018)

\section{Robotics.}

Even though robotics research has been performed for many decades, robotics adoption has not flourished. However, the past few years have seen increased market availability of consumer robots, as well as more sophisticated military and industrial robots. We predict that this will trigger wider adoption of robotics in the medical space for caregiving and other healthcare uses. Combined with DL (\#1) and AI (\#10), robotics will further advance in 2018. Robotics will also motivate further evolution of ethics (see \#8) (IEEE, 2018) 


\section{Ethics, laws, and policies for privacy, security, and liability.}

With the increasing advancement of DL (\#1), robotics (\#5), technological assistance (\#s 6 and 7), and applications of AI (\#10), technology has moved beyond society's ability to control it easily. Mandatory guidance has already been deeply analyzed and rolled out in various aspects of design (see the IEEE standards association document), and it is further being applied to autonomous and intelligent systems and in cybersecurity. But adoption of ethical considerations will speed up in many vertical industries and horizontal technologies (IEEE, 2018).

\section{Accelerators and 3D.}

With the end of power scaling and Moore's law and the shift to $3 \mathrm{D}$, accelerators are emerging as a way to continue improving hardware performance and energy efficiency and to reduce costs. There are a number of existing technologies (FPGAs and ASICs) and new ones (such as memristor-based DPE) that hold a lot of promise for accelerating application domains (such as matrix multiplication for the use of DL algorithms). We predict wider diversity and broader applicability of accelerators, leading to more widespread use in 2018. (IEEE, 2018)

\section{Maker Space}

A maker space provides hands-on, creative ways to encourage students to design, experiment, build and invent as they deeply engage in science, engineering and tinkering. A maker space takes collaborative elements from a science lab, crafts corner, computer lab or an art room to create something of an impact. On line of the modern approach to learning, maker spaces encourage students to consume and not just create, promoting learning through experimentation and creativity. Maker spaces are cross disciplinary and truly combine all the skill sets and knowledge students learn in other classes.

\section{Learning Analytics : The emergence of Little Data}

It is often said, "What gets measured is what gets done". The focus is shifting from big data to 'little' data. Little data is 
personal activity data which when analyzed by intelligent systems, is able to provide key insights into the way students learn. It may well become an important source of information and insight for decision-making for educators. It may also unlock new potential for personalization of tools and content. By adding the right information capture mechanisms and real-time insight capabilities, traditional Learning Management Systems (LMS) can now vastly enhance the teaching-learning experience. The implications of a data-driven approach will be far-reaching and will permeate not just teaching \& learning but other areas including guidance on career choices. Remote Proctored Assessments. New forms of technology-mediated assessments have enabled a big shift from fixed-in-point summative assessments, which are today at the core of the learning process, to more continuous and adaptive formative assessments. Remote Proctored assessment solutions are clearly more customizable, interactive, secure and quick to deliver with the pervasive use of broadband and technology. They work across multiple platforms (mobile included) and offer detailed interactive dashboards to analyze performance from various aspects. The ability to store historical assessment data and compare progress over time can be used to establish a trend and also draw inferences on the learners' progress in the context of learning. Online testing also brings in the benefits of anytime testing, remote proctoring, realtime audio-video integration and also more personalized testing.2018 promises to be an interesting year for education, clearly with edtech disrupting traditional methods, pedagogies and mindsets. Its seamless integration with print and classroom practices will be central to its success in the Indian context, and wider acceptance by stakeholders the key to its longevity! Companies like Wheebox have pioneered in this space and have grabbed major education campuses to move their high stake exams and certifications to remote proctored assessment technologies.

\section{Others:}

EMERGING Technology not yet used at scale 
- Immersive Technologies

- Conversational Systems

- Robotic Process Automation

- Machine Learning

- Contextual Workspace

- Digital Twin

- Blockchain

- Neuromorphic Hardware

- Quantum Computing

- ON THE HORIZON

- Technology or concepts in prototyping or design phase

- Autonomous Robots/Drones/Vehicles

- Intelligent Assistants

- Brain Computer Interfaces

- Human-Machine Convergence

- Advanced Robotics

- Bio Computing

- 4D Printing

- Uses of APIs

- Incorporation of mobile devices in teaching and learning

- Mobile apps for enterprise applications

- Technologies for improving analysis of student data

- Technologies for planning and mapping student educational plans

- Blended data center (on premises and cloud based)

- Predictive analytics for student success (institutional level)

- Database encryption

- (tie) IT asset management tools (e.g., CMDB)

- (tie) Student success planning systems(EDUCASE 2018)

- Complexity of security threats 
- Student success focus/imperatives

- Data-driven decision-making

- Contributions of IT to institutional operational excellence

- Increasing complexity of technology, architecture, and data(EDUCASE 2018)

\section{References:}

Prometheanworld (2018) Top 5 Education Technology Trends in education technology.(C2018 PROMETHEAN LIMITED .https://blog.prometheanworld.com/tech-insights/5education- technology-trend-in-2018/

Lexialearning (C) 2018 Lexia Learning ، 4 emerging Trends in Educational Technology for 2018 https://www. lexialearning.com/blog/4-emerging-trends-educationaltechnology-2018

Edtech (2018) 17 emerging trends. CWildfire Comms Ltd, Wildfire Comms Ltd, Unit 2.4 Paintworks, Arnos Vale, Bristol. https://edtechnology.co.uk/Article/edtech-201817-emerging-trends

Freiberger, Scott (2017) 5 Emerging Trends in 21st-Century Education. Getting Smart.

http://www.gettingsmart.com/2017/07/5-emerging-trends-in21st-century-education/

ISTE (2017). International Society for Technology in Education.https://conference.iste.org/2018/program/sear ch/detail_session.php?id=110834360

Rhea Kelly (2018) 7 Ed Tech Trends to Watch in 2018. Campus Technology(C) 2001-2018 1105 MEDIA INC, ED-TECH GROUP https://campustechnology.com/articles/2018/01/ 11/7-ed-tech-trends-to-watch-in-2018.aspx

Troo Tech (2017) 7 Key Trends for 2018: Innovation in Educational Technology. https://medium.com/trooblog/7-key-trends-for-2018-innovation-in-educationaltechnology-ff22b2d8f442, www.trootech.com

Matt J (2018).The 90 Hottest EdTech Tools According to Education Experts.https://tutorful.co.uk/blog/the-82- 
hottest-edtech-tools-of-2017-according-to-educationexperts

Meghan Bogardus Cortez (2018). 5 Technology Tools in the

Higher Education Classroom. https://edtechmagazine. com/higher/article/2018/03/5-technology-tools-highereducation-classroom-perfcon

ROBERT HAWKINS (2010) Global Trends in ICT and Education edu tech:http://blogs.worldbank.org/edutech/10-globaltrends-in-ict-and-education

Trend Report (2018) Emerging Technology Trends. https://www.sap.com/documents/2018/04/02112563007d-0010-87a3-c30de2ffd8ff.html

Jürgen Müller (2018) Trend Report 2018 Emerging

Technology Trends. file:///C:/Users/maka/Downloads/ 02112563-007d-0010-87a3-c30de2ffd8ff.pdf

Beacon (2018). Top 5 Trends to Lookout for Education

Technology in 2018. www.eklavvya.in India, beacon. 2018.https://www.eklavvya.in/ebook/Top $\% 205 \% 20$

Trends\%20to\%20Lookout\%20for\%20Education\%20Tech nology\%20in\%202018.pdf?utm_content=bufferdde4b\&ut m_medium=social\&utm_source=plus.google.com\&utm_cam paign=buffer

IEEE (2017).Top 10 Technology Trends for 2018, IEEE Computer Society Predicts the Future of Tech. COMPUTING SOCIETY2017.https://www.computer.org/web/ pressroom/top-technology-trends-2018

Nirmal Singh (2017). Top 10 Trends In Education Sector.BW BUSINESSWORLD.https://www.gartner.com/en/ information -technology/insights/trends-predictions

GARTNER (2018). Master Today's Technology Trends. EDUCAUSE Center for Analysis and Research (ECAR) https://library.educause.edu/resources/2018/1/highereducations-top-10-strategic-technologies-and-trends-for2018

Research Hub (2018).Higher Education's Top 10 Strategic Technologies and Trends for 2018 
